\title{
Severe hypotonia-psychomotor developmental delay-strabismus-cardiac septal defect syndrome
}

INSERM

\section{Source}

INSERM. (1999). Orphanet: an online rare disease and orphan drug data base. Severe hypotonia-psychomotor developmental delay-strabismus-cardiac septal defect syndrome. ORPHA:467176

Severe hypotonia-psychomotor developmental delay-strabismus-cardiac septal defect syndrome is a rare, genetic, non-dystrophic congenital myopathy disorder characterized by a neonatal-onset of severe generalized hypotonia associated with mild psychomotor delay, congenital strabismus with abducens nerve palsy, and atrial and/or ventricular septal defects. Cryptorchidism is commonly reported in male patients and muscle biopsy typically reveals increased variability in muscle fiber size. 